\title{
Regional Integration in the Horn of Africa: Some Findings
}

\author{
Binyam Yitay \\ Tsoaledi Thobejane \\ Universiy of Venda, South Africa
}

\begin{abstract}
In the Horn of Africa there is a regional bloc that comprises eight countries namely Djibouti, Eritrea, Ethiopia, Kenya, Somalia, Sudan, South Sudan and Uganda. The appellation of the organisation is called IGAD (Intergovernmental Authority on Development). It was established in 1986, yet it could not bring a desired result. Even the least form of integration i.e. Free Trade Area (FTA) could not achieve. So that this paper will probe the challenges associated with the regional integration agenda of IGAD. This paper is an excerpt from a study conducted by the author regarding IGAD. Thus the paper will present the findings of the said study. The study used qualitative approach for data collection. Interview with IGAD officers has been conducted to know the cause for the failure of IGAD's integration process. IGAD lacks both financial and human capacity to fulfil its objectives, absence of regional institutions (such as Bank of IGAD) worsen the situation, emerging and subsequent security threats such as terrorism, pastoral conflict, tense relationship among member states, undermining of the informal trade remains the road block of regional integration.
\end{abstract}

Keywords: Regional Integration, Horn of Africa, Economic Growth, IGAD

\section{Introduction}

This paper focuses on the findings that emerged from the data. It also discusses the themes that emerged from the interviews relating to regional integration in the IGAD region. The main purpose of this study is to probe mechanisms through which the IGAD regional integration programmes could be achieved and how these mechanisms could contribute towards the socio-economic growth of IGAD countries.

Specific objectives of this paper are as follows:

1. Explore the core socioeconomic and political challenges that hamper the regional integration agenda of IGAD,

2. Investigate the appropriate measures that could be taken by IGAD to remedy the situation and describe whether these actions address the organizational challenges of IGAD's regional integration endeavors,

3. Probe the best practices that IGAD might take from other regional groupings within or outside Africa.

In order to meet these objectives, the researchers interviewed IGAD officials in Addis Ababa and Djibouti. The researchers followed research ethics procedures and the interview was made with unreserved consent of the interviewees. The Headquarters of IGAD is in Djibouti while its peace and security branch is located in Addis Ababa. The interviews were conducted with five officers of IGAD. These officers have immense knowledge on the IGAD regional integration process. They are high profile individuals and were selected by the researcher for their potential to provide the requisite information.

Table 1. Biographic data of respondents

\begin{tabular}{|l|l|l|l|l|}
\hline Name & Age & Qualification & Position in IGAD & Country \\
\hline Andrew & 38 & MA: economics & $\begin{array}{l}\text { Director: Division of economic } \\
\text { cooperation and social development }\end{array}$ & Uganda \\
\hline
\end{tabular}




\begin{tabular}{|l|l|l|l|l|}
\hline Hussein & 49 & MSc: IT, Diploma In library science & $\begin{array}{l}\text { Director: Information, documentation \& } \\
\text { knowledge mgt division }\end{array}$ & Djibouti \\
\hline Johannes & 54 & MA: economics & Head: Transport and communications & Sudan \\
\hline Kendrick & 45 & MA: Infrastructure development & $\begin{array}{l}\text { Director: Infrastructure development } \\
\text { division }\end{array}$ & $\begin{array}{l}\text { Kenya } \\
\text { (ISSP) }\end{array}$ \\
\hline Trevor & 48 & MA: conflict resolution & & Ethiopia \\
\hline
\end{tabular}

The data were captured between the time of April 18 to June 10, 2016 in Djibouti and Addis Ababa. After analyzing of the data, the following themes and sub-themes as shown in Table 2 below emerged:

\section{Table 2. Emerging Themes}

\begin{tabular}{|c|c|}
\hline Main themes & Sub themes \\
\hline 1. Factors related to Capacity building within IGAD & $\begin{array}{l}\text { 1.1. Financial capacity } \\
\text { 1.2. Dependency on donor funds }\end{array}$ \\
\hline \multicolumn{2}{|l|}{ 2. Lack of feasible infrastructure in the region } \\
\hline 3. Harmonisation of policies & 3.1. Bilateral agreements \\
\hline 4. Challenges of free movement of people & $\begin{array}{l}\text { 4.1. One stop border post } \\
\text { 4.2. People to people interaction }\end{array}$ \\
\hline 5. Effects of political factors on regional integration & $\begin{array}{l}\text { 5.1. Lack of political will and commitment } \\
\text { 5.2. Coinciding membership }\end{array}$ \\
\hline 6. Lack of peace and security & 6.1. Terrorism \\
\hline
\end{tabular}

\section{Factors related to capacity}

Capacity refers to the ability of achieving projects with adequate human and financial means.

In this regard, Andrew (Participant 1) stated the following:

"IGAD has the potential of becoming one of the best organizations in Africa should it adhere to all its policies that it has adopted since its inception."

Kendrick (participant 2) also supported the views of Andrew and said that IGAD had capacity challenges associated with the structure. The structure of IGAD has never changed since its inception. It is so archaic that it hinders the organisation from moving forward. In line with this, Dan (2010) wrote that the secretariat's ability is highly restricted by a top down decision making structure. The Assembly of the Heads of state is the ultimate decision making organ and this hinders a participatory method of decision making.

Kendrick continued by saying that the organization does not have a clear programme on how to deal with disasters such as drought in the Horn of Africa. In this vein, Abdi \& Seid (2013) indicated that member state countries should strive to act closely based on what type of regional integration or cooperation would achieve specific objectives of the organization.

In addition, Kendrick said that:

"Subsequent trainings have been offered. Project management, monitoring and evaluation training is given to project officers. Gender and conflict workshops are also organised. But it seems as if these trainings do not yield any results."

Trevor (participant 3) agreed with Andrew and Kendrick by stating that IGAD had capacity challenges but it is not something that is related to lack of knowledge and skills among IGAD officers. In certain areas, it needs specialists and professionals while it also needs resources.

In addition, Andrew bolstered his argument by saying that: 
"We have quite a lot of capacity building programmes that are supported by our partners. But I can never say that we have adequate resources. IGAD needs improvement. If you have the adequate capacity, the implementation of the policies will be easier."

Hussien (Participant 4) also supported other respondents by saying the following:

"We cannot talk about IGAD in isolation. This organisation represents member states. If it fails, it means all of the states are failing. So the capacity of IGAD should not be limited to the Secretariat. It is also within the mandate of member states to make sure that it delivers. This is their organisation. Member states failed to compliment staff even when there was a serious need to address conflicts and other forms of disasters. The ultimate mandate of IGAD lies at the top of its hierarchy - i.e. the summit or the Assembly. So the capacity problem is caused by the member states that give IGAD narrow mandates and inadequate capacity. The actual implementation of all IGAD projects is done by member states."

Johannes (Participant 5) also acknowledges the capacity challenges of IGAD. According to him, the capacity problem of IGAD might be serious but not critical. He further said that there is a way out if member states can look for a solution. He expanded his argument with the following sentiments:

"Sometimes you might have heard a lot of generalized statements about lack of capacity in the organization. But when people are criticizing they just look at the weaknesses. They do not look at the strengths. So sometimes those statements are not balanced because one could not say that you are not doing well rather he must point out the areas that you are weak at."

Johannes further said that IGAD has the capacity to address these problems but it is also the responsibility of member states.

\subsection{Financial capacity}

All the respondents stated that the financial capacity of IGAD is at its lowest. Kendrick said that in terms of financial capacity, there are challenges. Johannes said that "IGAD is financially weak. Financial weakness hampers the ability of implementing its policies. Johannes further said that lack of an IGAD Development Bank worsens the situation. IGAD needs to have its own resources rather than depend on donors or partners. Member states of IGAD are only paying the salaries of IGAD officials. The real programs are run by donor funds. So each partner has their own agenda. So if it really wants to move forward, IGAD must have its own resources. In a nutshell, IGAD has to develop its own development bank."

Financial incapacity of IGAD, according to Hussien, leads to a narrow agenda that does not address the overall needs of the member states.

\subsection{Dependency on donor's funds}

All the respondents mentioned that dependency on donor funds is not a problem and there is no influence by donor countries. According to Trevor:

"Donor countries express their interest and their focus. You cannot use that money beyond their commitment earmark. For instance, Japan gave us USD $\$ 750$ Million to counter terrorism in Somalia. Japan's interest is Somalia, IGAD cannot use that money to develop Kenya or Uganda. In the aid politics, there is no free lunch. In fact, they might not twist your hand and say to you, do this and don't do that. However, one way or another they impose their interest."

Hussien said that, IGAD is dependent on partner funding, explaining that;

"In the $20^{\text {th }}$ century, it is a fact that developing states are dependent on developed countries to secure funds for both national and regional projects. It is also a fact that if you do not have the capacity to buy a car, you may borrow money from the bank or other sources. I think all the issues of regional integration are controlled by national interest. Member states have their own interest." Hussein said that even if we depend on donors, we have to bargain in order not to lose our integrity.

Kendrick also supported Hussein's view. He said that dependency on donor countries is not influencing the regional process of IGAD. Kendrick thinks that having funds from external donors is not a problem in the first place and it does not bring any influence on the proposed projects. "If a project is relevant to the citizen and if you have the ability to borrow by all means 
borrow and do it. There are a lot of people saying that it is not good to rely too much on foreign funding. However, regional projects are capital intensive, if you do not have the resources, it is wise to get these somewhere else. The benefits outweigh whatever costs that means there is no problem on the foreign aid IGAD depends on. If there is capability of getting funds, it is better to limit the conditions and scope of the donating country", said Kendrick.

In addition, all respondents said that IGAD has development partners. There is also an IGAD Partner Forum (IPF) that constitutes the donor countries of IGAD. IPF is established to facilitate the flow of funds from partners to IGAD's projects. So far, the member states appear not to be funding a lot of regional projects of IGAD. Instead, there is over-reliance on funds from developed countries.

Johannes agreed with the other respondents that dependency on donor funding is inevitable due to lack of regional financial institutions. According to him, the challenge of dependency could not be alleviated until IGAD is able to establish a development bank. According to Trevor and Hussien, the partners of IGAD are also benefiting in one way or another when they allocate funds for projects.

\section{Lack of feasible infrastructure}

Infrastructure includes the construction of roads, railways, ports, power and communication facilities. In this regard, Johannes said that IGAD is presently making road connectivity that measures about $5000 \mathrm{~km}$. According to Johannes, IGAD is a facilitator for making the projects. In addition, IGAD is instrumental in making energy (power), telecom, and railway connectivity.

Hussien supported Johannes's view by saying that, "in terms of connection, we are connecting capital cities with ports, which is the first step towards development. We have the main road connection but it needs sub-roads because integration is about the entire people not just connecting the capitals."

According to Kendrick, IGAD facilitates the interconnection of trans-African Highway number 4, which links Cape Town and Cairo. The missing link of this Highway was in Kenya between the borders of Siweru and Moyale in Ethiopia. This missing link is expected to be completed at the end of 2016. For a region to be connected, people should be able to move as well as goods. For all practical purposes infrastructure is one of the main drivers of the integration process.

Andrew and Trevor supported the notion that infrastructure is one of the key drivers of integration. Both said that there are infrastructure challenges for IGAD to speed up its integration process. In the aviation industry; there is no network among airlines of the region. The only airlines that fly across the region are Ethiopian and Kenyan airways. At least those airlines connect the capital cities of certain member states. Hussien and Trevor said that the region's airways are not enough to cover the whole region and the price of airfare is too high. In line with this, Gerald (2012) also observed the high cost of transport in the region which is associated with lack of harmonisation of transport policies.

In relation to the cost of developing infrastructure, Johannes said that it is quite expensive. Johannes added that it was expensive to communicate especially across borders. The calling rate of the region is quite expensive. According to Johannes, there are two kinds of regional integration challenges in the IGAD region, these are physical and non-physical barriers.

Andrew agreed with Johannes and stated that:

"Sometimes it is easier to call the USA or UK than to communicate with the next door member states. Why I would have easier access to communicate with the outside world than with my own people still confuses me to date."

Physical barriers refer to solid road blocks of regional integration. The majority of respondents said that physical barriers refer to infrastructure such as road, railway, and airways. The non-physical ones were identified as visas, immigration regulations and policies in general. In order to address the problems of non-physical barriers, political will and commitment are the two prerequisites. The regional integration process in general has tariff and non-tariff barriers. The imposition of heavy tariffs on goods that pass through member states is the main challenge for the promotion of FTA in the region.

Trevor agreed with the others on the main challenges of IGAD in advancing connectivity projects. He said that "we need more projects on connectivity of roads. With the addition of the problem of donor fatigue due to duplicated projects in the South-Eastern Africa region, the infrastructure projects suffer from lack of sustainable financial contributions." 
Hussein agreed with Trevor that in infrastructure connectivity, roads were being rehabilitated and undergoing maintenance. These roads will have to be regulated within the law. When constructing a road, according to Kendrick, there must be quality control. In addition, there must be maintenance. Lack of routine maintenance is exacerbating the poor state of infrastructure in the region. Routine maintenance includes even mundane issues such as cutting the grass, opening the caravan and mending the boreholes.

Johannes agreed with Kendrick's opinions. He said that when an infrastructure is designed, there should be some predetermined costs, including the cost of renewing. If there is a failure to maintain projects, their sustainability can therefore not be guaranteed. Lack of adequate maintenance resources remains the challenge of infrastructure development in the region.

All the respondents said that the involvement of the private companies in the infrastructure sector is so limited. According to the respondents, when it comes to regional projects, companies mainly involve themselves as contractors or consultants. Private companies are only involved in the power construction sector, telecommunication and the development of ports. Due to the very fast remittances, private companies are often involved in the telecommunication business sector. If you look at the telecom industry, you will notice that there are a number of private companies in the region. In Kenya, the telecommunication sector is dominated by the private sector. In Uganda, it is the same. The initial capital of the telecom industry is not so high and the remittance is higher and faster. The private industry is a business driven system.

All respondents agree that, on roads connectivity, IGAD does not involve private companies. The road tender is mainly given to government companies because infrastructure is very expensive. Road, railway and other related constructions can only be serviced through the funds of the governments which are member states. Private companies are profit-oriented. They have difficulties in funding road projects. Infrastructure is capital intensive because of this. IGAD prefers government companies than private ones.

\section{Harmonisation of policies}

One of the most vital elements of the integration process is harmonization of policies. In response to this, Kendrick said that the harmonization of policies poses a lot of challenges. IGAD had some meetings among transport ministers of member states regarding harmonising of vehicle carrier policies and licensing. It must be noted that the IGAD secretariat can only make recommendations at a technical level regarding policy changes pertaining to the harmonisation of, for instance, vehicle policies. The ultimate decision on harmonisation of policies and their enactment lies with the summit of heads of states.

Kendrick agreed that the process is quite tedious and difficult. Recommendations continue to be made to ease the burden that the IGAD faces regarding the above problem. Also, it should be noted that it takes time before recommendations are addressed. Making policy out of these recommendations involves another tedious process which takes time.

Trevor stated that the harmonisation of policies is difficult to implement in the region. IGAD could not force states to harmonies their laws because of the principle of sovereignty. The most difficult barrier in harmonization of laws is sovereignty. States have to surrender their sovereignty to empower IGAD with policy making. In line with this, Kasner (1983) contended that harmonisation of policies could be implemented only if states are ready to relinquish certain portions of their sovereignty.

IGAD is also working with Kenya, Uganda, Sudan, South Sudan and Somalia to draft policies which are user-friendly. Gradually, this cooperation will upgrade to harmonisation of other policies. At least for now, there is a platform and framework to go about implementing these policy recommendations. IGAD is also in the process to establish regional platforms for regional issues to address and resist, the emerging and evolving problems of the region.

Hussien agreed with the other participants that the attainment of harmonisation of laws in the region was still a long way off. He said that:

"If you take the ICT, it is too costly, bringing these to our side must have been quite a lot of investment. The bottom line is usually profit for those companies that brought those technologies. Even delivering the IC for the people of the region is a problem let alone harmonising ICT policies. This is because, we have a lot of legacies, ideology, technology or thinking that we continue to contend with in this day and age. And these do not help us to get to where we want to go as IGAD. States also have also shown some dislike of some of the features of technology. Do you stop some using skype to talk to relatives 
or business partners? Some states fear that certain information available to the citizenry may be politically insensitive and may result in some form of the "Arab spring" which caught Egypt by surprise. There is quite a lot of harmonising to be done."

\subsection{Bilateral agreement}

Hussien believes that regional integration takes time as it needs a lot of negotiations. The IGAD region has different nations that have diversified interest, but they still rely on each other. Ethiopia and Djibouti, for instance, rely heavily on each other for survival. Most of the food from Djibouti comes from Ethiopia and some commodities are also from Djibouti. There are so many Somalia businessmen in Kenya while there are Ethiopian and Ugandan business persons in Djibouti. Some industries in the South Sudan are predominately owned by Eritrean investors.

Kendrick supported Hussein's view that the bilateral agreements of member states in various sectors are flourishing. "It seems that a lot of negotiations and work has been done bilaterally. However, IGAD lacks the capacity to regulate and rationalize bilateral agreements so that they become regional", said Kendrick.

Andrew agreed with Kendrick and Hussien that member states should be able to sign bilateral agreements in order to expedite regional development.

Johannes also supported the views of the other respondents by saying the following:

"I told you that infrastructure is one of the main drivers of integration. We are doing very well in terms of connectivity. Our members are doing a commendable job bilaterally."

Trevor also supported the view of Johannes as follows:

"Ethiopia and Djibouti are the greatest trading partners. These countries are trading with their neighbours and they have a lot of bilateral arrangements and are working together. For me this is one of the giant steps towards integration. If you check Sudan and Ethiopia, you will also find that the two countries are working together. Kenya and Ethiopia are also working together as well as Kenya and Uganda and Kenya and South Sudan. What I can tell you is that even Ethiopia and Somaliland have found the urge to work together."

\section{Challenges of free movement of people}

For Trevor, the movement of people is limited due to a tense relationship between IGAD member states. He added that in the Sudan-Uganda, there is no free movement of people because of the rivalry between the two, resulting in the closure of the border since the 1998 war. The Sudan-South Sudan border does not entertain free movement of people because of territorial claim and the unresolved issues. The Kenya-Somalia border is not that much suitable for the free movement of people because of the threat of terrorist attacks.

Kendrick supported Trevor's view that the integration process should enable the movement of people and goods as smooth as possible. Andrew also said that in the IGAD region, movement of people is difficult.

Johannes agreed with Andrew and Kendrick by articulating that:

"We have to develop the protocol of free movement of people. If heads of governments pass this protocol, it will have a lot of use. After the approval of the protocol, it gives people of the region the right to establish residency and business."

Hussien said that a lot of work has to be done to enhance the movement of people. The people of IGAD have to interact within the region. This is the starting point of future integration. As a citizen of the IGAD region, there should be minimum problems to move from one member states to another one, and at least visas should be issued on arrivals.

In a nutshell, all respondents agree that the movement of people should be allowed for legal, formal or informal, economic or political as well as social or environmental reasons.

According to the respondents, IGAD should also be on the lookout for trafficking activities. Thus far, there are three routes of the trafficking "industry", namely,

1. Europe - that crosses Sudan, Libya, Egypt and the Mediterranean Sea; 
2. Middle East - via Ethiopia, Djibouti, Somaliland to Yemen and Saudi Arabia;

3. South Africa - this is a dangerous route that people were forced to cross six countries to reach their destination. Most Eritreans, Ethiopians and Somalis are travelling through this route.

Johannes said that people still prefer illegal routes to migrate. In 2014, many Ethiopians were chased from Saudi Arabia and most of them went back using illegal routes and traffickers. Most of the trafficked are fascinated by the good economic prospects in foreign countries.

Andrew further lamented that "We do not need a visa to visit our intertwined countries. Our movement is hampered by the strict requirement of visa and these strict procedures are discouraging people from doing business amongst themselves."

\subsection{One-stop border post}

Andrew explained the principle as follows:

"One-stop border posts essentially means when you are travelling from one side of the border with or without goods. Once you clear your documents at border one for instance, you do not have to do the same at border two. These documents should be able to be captured electronically. The migration officer at the other side of the border should just check the documents and make an entry stamp."

Trevor supported the views of the other respondents by saying that modern equipment like scanners can help in the screening of trucks without offloading all those shipments. Trevor further explained that:

Information can come to border officers before the people and trucks arrive.

Kendrick also supported the principle of one stop border post. He said that:

"For people to be integrated, they need to move from one place to another to trade. For that to happen, you have to have the necessary infrastructure."

All the respondents are in agreement that the border areas are HIV hot spots. In this regard, the respondents said that IGAD has a regional HIVIAIDS programme that focuses on cross borer population that migrate a lot. These are the truck drivers, refugees and cross border traders. In support of the respondents Gerald (2012) indicates that, a fundamental principle for sustainable development is that human being. Wellbeing that is health, wealth and quality of life of people is part of and linked to the diversity, productivity and quality of the ecosystem of the region.

\subsection{People-to-people interaction}

Slocum and Langenhove (2004) indicated that beyond trade and tariffs, regional integration should be conceived of as a dialectical unity of social, economic and political processes." The New Regionalism Theory also stated that integration process should involve non-state actors including the people (Hettne, 2010). It results in the diffusion of political power from centralised state to other actors such as the people themselves (Laursen, 2008). It is in this vein that Hussein stressed that IGAD should normalize and harmonies border polices of member countries so that border towns can share resources especially that people along the borders are the same in terms of culture, race and linage. Hussein further said the following: "The relationship is already there. Even in the economic sphere, unregulated commerce is conducted in border areas."

Andrew agreed with Hussien that member states have to strengthen the interaction between people. In the border area, there is an informal socio-economic interaction between people of two or more countries. Andrew added that the border area might be divided by boundaries but residents of the area have blood relationship. They get married to each other. "In some areas, you have so much migration of people because of the nomadic lifestyle where they stay during winter and move to the other area later", indicated Andrew.

The other feature of people-to-people interaction is informal trade. All the respondents said that, if one goes to the borders people are the same on both sides. They trade between each other but this trade is unrecorded and registered by member states. Kendrick added that Moyale is a border town between Kenya and Ethiopia. People of Kenya work and sleep in Moyale. They move around, go to the cattle market on the Ethiopian side and buy whatever they want. In fact, such kind of 
common market will reduce conflict among pastoralist communities. According to the study conducted by the World Bank (2014) and ECA (2006) frequent and increasing trades will reduce conflicts by about $17 \%$.

Hussien agreed with Kendrick that if one goes to Kenya and Uganda, there are two border towns on either side. These are Marba border and Bsiya. In fact, some people even farm on both sides. In terms of cross-border trade, the informal transaction is already there. There is a lot of trade but this trade is not formal but informal. Here, the boundaries are artificial and separate family members. For example, one may have relatives on the other side of the border.

\section{Effects of political factors on regional integration}

\subsection{Lack of political will}

According to Johannes, political will and financial means are the key drivers of integration of which without them one cannot talk about integration. Johannes added that once the political will is there the other drivers will follow. In support of this Kidane (2013) stated that political setting is the foremost component foe the success of integration process. In addition, Draper et, al. (2007) indicated that in Africa politics is the major driver of integration.

The majority of the respondents agreed that political will and other drivers of integration are pillars of a region. They are connected to each other. Member states must harmonize their developmental policies. The harmonization of policies has been done everywhere from Latin America, Europe, EAC etc. Andrew added that the systems have already been developed, provided that member states render their political will or agree on the matter. They are the ones responsible for signing the agreements and not the Secretariat. Biswaro (2005) also support this view that nations could only integrate with their free will rather than coercion. This contention was raised by Haas (1964) that states has to redefine their national interest to regional perspectives based on their will.

Kendrick said that the decision of summits should be implemented by member states. Making deliberations in the annual meetings is not sufficient. However, for regional integration to be a reality the meetings should be coupled with implementation and political will. The ratification of protocols demands political will from each member state.

Trevor indicated that there was lack of cooperation among member states due to the tense relationship each state had with the other. He added that the relationship between Ethiopia and Eritrea is not cordial at the moment. Similarly, the relation between Eritrea and Djibouti is not healthy. The South Sudan and Sudan relation is not good since they did not have clearly demarcated borders. There is tension between Sudan and Uganda because of previous political squabbles.

For Hussien, IGAD is just a secretariat that implements decisions of member states and the commitment of member states determined the achievements of the secretariat. Hence, when one mentioned the problems of political will and commitment, it directly reflected on the heads of states. These are the main actors of the integration process.

Johannes also agreed with the other respondents that the protocol for free movement of people had been adopted. The protocol promotes the right of establishing business, work, education (e.g. Universities). But heads of states are the ones that should ratify the protocol. In line with what Johannes said, Layne (2006) further stressed that despite abundant declarations, measures, policy statements, political commitments, and intra-national institutional configurations, there is little advancement in forwarding clear and breakthrough guidelines for policy makers and researchers.

Andrew supported the views of other respondents that member states lack trust for each other and the integration process. Due to lack of trust member states are not willing to do tasks that benefit the entire region. Instead of rendering political will and commitment for the regional project, member states prefer to construct roads that will connect them with a "trustworthy neighbour" country. The road between Ethiopia and Sudan was constructed through bilateral agreement between the two countries. The interconnection has been done by the countries. This shows that if member states are committed, they will facilitate the integration process. In supporting this view, Layne (2006) stated that member states have to forego their national interest for regional common good.

Besides, member states are also competing to get the status of hegemonic state. According to Trevor, Ethiopia and Kenya behave like the hegemonic states of the region. For Trevor:

"The term hegemonic is difficult to understand. In ECOWAS, Nigeria is a hegemonic state, it has political influence, big economy and strong military. In the SADC region, South Africa can be classified as the hegemonic state due to its vibrant economy. If you look within the IGAD perspective, Ethiopia looks like a hegemonic country. Ethiopia's fastest growing 
economy makes her more viable to become a hegemonic power. Ethiopia has political influence and a strong military. Besides, the population of Ethiopia is by far large and greater than the sum of Kenya and Uganda. Population by itself is power. Kenya is another emerging hegemonic power because of her good economic standing, except that the country is mired in corruption scandals. I am therefore pessimistic about the political will of the member states when it comes to the amelioration of hegemonic power in the region".

Andrew agreed with Trevor noting that lack of hegemonic power in the region could be one of the challenges of regional integration. He added that states of the region are not in good standing to nominate the region's hegemonic state, but Ethiopia will be a hegemonic state since geographically it is situated at the centre of the IGAD region and shares a border with all IGAD members except Uganda. This is supported by Nomvete (2009) when he stated that there must be at least one big or powerful state in a region, which is imbued with either socio-economic or political power or popularity in the international arena. Ethiopia as the location of African Union headquarter could regard as popular state in the international community.

Johannes supported Andrew and Trevor's views noting that Kenya could be a hegemonic power of the region. However, the country has been targeted by terrorists leaving Ethiopia as the most stable country in the region, hence placing Ethiopia in a better position to become the hegemonic state of the region.

\subsection{Coinciding membership}

Trevor noted overlapping membership is a problem. Kenya and Uganda are member states of EAC. All member states except Somalia are members of COMESA. Djibouti, Eritrea, Sudan and Somalia are members of CEN-SAD. Trevor noted that, dual accountability and dual membership affects member states' ability to attain their priority and commitment. This contention is also supported by Estrada (2009) when he indicated that regional integration may contribute to international frictions between competing blocs through creating multiple legal frameworks and various dispute settlement mechanisms as well as absorbing other multilateral arrangements.

Johannes agreed with Trevor's and Estrada's view that overlapping membership makes member states to be uncommitted. The most problematic consequence of coinciding membership was that it brings overlapping programs. Previously there was an Inter- Regional Coordination Committee that gave recommendations on projects of building a road. According to Johannes, although there was a tender for overlapping programs, it lacked coordination among different RECs of the South Eastern Africa including SADC, COMESA, EAC, IOC and IGAD.

Andrew and Hussein bolstered the views of the other respondents by saying that the Tripartite Agreement (TA) is just a political agenda that has nothing to do with the reality. In the beginning one has to finish what he is doing in the IGAD region. Jumping from one configuration to another is meaningless. The TA is an agreement between COMESA, SADC and EAC where they agreed to work in the infrastructure projects. But practically, all the three organisations did their own projects without engaging IGAD. A study conducted by IGAD (2011) also confirm that due to overlapping projects, donor countries considered the organisation as political group because many projects of IGAD is also run by COMESA. Indeed, overlapping of regional projects create confusion on donor countries and development partners. It creates paradox on which project should get funded.

\section{Lack of peace and security}

All the respondents said that the best achievement of IGAD lies in the peace and security sector. Hussien said that, IGAD achieved quite a lot of mediation and peace security tasks. However, its achievement in the Sudan and Somalia peace process is still far from over. In relation to this Peter (2012) enunciated that integration will lead to not only on economic unity but also cooperation in the peace and security sector. Redie (2013) also stated that regional integration in the region could serve as a resolving mechanisms for pastoralist conflict over grazing land and water. A sound regional policy could reduce socio economic problems.

In light of the above, Trevor said that:

"Even though IGAD has been grappling with extraordinary circumstances, the IGAD mediation process is successful so far. Both the Sudan and Somalia peace processes are effective. In Somalia at least the federal government is established. It is a success story. The impending Comprehensive Peace Agreement (CPA) between South Sudan and Sudan is also a 
success story of IGAD. In addition, the peace accord between President Salva Kir and Rick Machar is also a success story. But the problem is that there remains an emergent conflict that borders on religiosity."

Andrew also agreed with Trevor by saying the following:

"I think those extraordinary issues are spoiling the achievements of IGAD. However, if you look at the issue of peace and security, IGAD has been able to establish the Sudan peace process. When Sudan separated with South Sudan, IGAD is the one that midwifed the process. IGAD has been working with Somalia including the rebel groups. With limited resources, IGAD is doing well in the peace and security sector. This clearly shows despite whatever happens, we are on the right track. Even if people from outside might not agree, we have a good record especially in the peace and security sector."

The majority of respondents said that the IGAD region was notorious for frequent conflicts and wars. According to the World Bank report (2013), since 2005-2011, there were a series of attacks by pirates and warlords in the region. As a result of that, Euro naval forces and many actors were drawn to the offshore of Somalia to protect European interests. Because of this intervention since 2011, piracy declined. Indeed, this trend of piracy in Somalia and the weak political system makes the country to be one of the weakest in the horn of Africa (World Bank, 2013).

Johannes, also a participant, said the following: "Eritrea also suspended its membership from IGAD. We don't know when it intends to come back. It is part of the consequence of the Ethio-Eritrea border war. South Sudan is part of IGAD but suddenly war broke out in its mainland, right in the capital city called Juba. The Eritrean government captured parts of Djibouti. Somalia is also a failed state for the last 25 years. On the overall, things are not well in this part of the world."

Kendrick also reflected on the views of Andrew and Johannes. He said that:

"Member states are more committed with conflict resolution efforts. If one looks at the meetings held by member states for Somalia and South Sudan, you will find that there have been many. South Sudan now is committed to peace. The same is true about Somalia. Stopping internecine conflicts means a lot to the development of the region."

Hussien also agreed with Kendrick that organised transnational crimes affect the socio-economic development of the region. Hussien added that arms trafficking, money laundering, insurgent groups, and terrorism were the main security challenges of the region which compromised the integration process. Money laundering was affecting the financial integration of the region while insurgent groups were involved in the demolition of regional infrastructure in order to unseat the central government.

For Hussien, one cannot control the insurgent movement unless the incumbent forces win or lose. He said that one has to know the reality. In Ethiopia, there were civil wars for more than three decades. There was mediation and discussion but it did not bring any solution. Finally, the one who won the battle came to power.

Trevor supported Hussien's view that the Sudanese civil war is the longest one in Africa. Many mediations were conducted but neither of the parties agreed to cease their warfare. At last the civil war came to an end with the secession of South Sudan.

The majority of respondents believe that IGAD's engagement with the media is quite limited. This is due to the different policies of member states towards the media. The respondents also worry about the growing negative impact of social media. The Information Resource and Communication Centre of IGAD is responsible for liaising with the media. It is faced with challenges. Johannes and Kendrick emphasised the need for inclusiveness in IGAD's mediation process. Accordingly, IGAD's peace process is an inclusive one as it involves civil societies, elders, warring factions, international institutions (Such as African Union), interested countries, and IGAD partners.

Hussien supported this view and said that:

"IGAD is neutral in the mediation process. In the CPA, IGAD was mediating the South Sudan and Sudan. It was mediating as a neutral partner. CPA is too vital to bring relative peace in Southern Sudan."

\subsection{Terrorism}

Andrew noted that terrorism is one of the major challenges of regional integration. The frequent attacks such as in Kenya affects the country in many ways. It affects the country's stability and its cost of life, the cost of finance as well as the tourism 
industry. This was witnessed by the recent attacks by Al Shabab on the 11 April 2015 at Garissa University where almost 147 Kenyans were killed (ISS, 2015). The same is true about other countries such as Ethiopia, Uganda and Djibouti which are embroiled in terrorist activities. Andrew emphasised that even profiling and labelling has its negative impact on socioeconomic development. After 9/11, travelling to US or Europe with a Muslim name was not easy.

Hussien added that the same is true for peaceful Somalis who want to travel across the IGAD region and also to the United States of America since President Trump was sworn into the oval office. They are interrogated and watched out by immigration officers. Even if a religion could serve as a pretext to mobilize people to engage in terrorist activities, it will be a bad deduction to associate all sects of Islam with terrorism.

In supporting Hussein, Victoria (2011) maintains that religion as a means of controlling state power is not a new phenomenon. She indicates that there were the Jacobins in France that indorsed for the origins of terrorism in the $13^{\text {th }}$ century. Other terrorists that justify their acts as religiously correct include Irish Republican Army, National Organisation of Cypriote Fighters, Muslim National Front in Algeria.In line with this, the majority of respondents believed that terrorism and radical Islam have a nexus relationship. Kendrick said the following in this regard:

"Radical Islam is a problem. Definitely Radicalisation is a challenge. This is because of our proximity to the Middle East conflict centre. This proximity makes us highly vulnerable. In addition, the Somalia crises aggravated the problem of radical Islam. Somalia became a theatre for foreign fighters, foreign ideology and narratives that are beyond the doctrine of Islam." This is in line with Dawit (2016), who indicated that Wahhabism, which is also part of the radical Islam, is a problem in the region in that it does not tolerate other forms of religion. He further stated that Wahhabism observesa strict interpretation of Islam, condemned other interpretations and innovations and it saw Western values and civilization as abhorrently evil. Dawit's assertion was also made true by the US state department's reportabout the beheading of two Muslim clerics from Shi sect in Somalia (US state Department, 2009).

The use of force to defeat terrorist groups like Al-Shabab is not working. The best way is to study the root causes of terrorism. According to a study conducted by Institute for security studies (2015), the brutality of security forces within IGAD is mentioned as the reason instigating the citizens to join terrorist groups. Attin and Willian (2007) also argue that economic factors in this region are the root causes of terrorism. Furthermore, poverty might lead the unsatisfied youth to join terrorist groups.

\section{Conclusion}

This paper presents the opinion of the respondents. Most of them revealed that IGAD lacks financial capacity, unclear programmes and a static structure that hampers the secretariat to work effectively. It was also revealed that regional projects are depending on donor countries since IGAD lacks financial institutions that could develop its own source of funding. Presently, IGAD is engaging the member states in building roads that could connect all the countries in the horn of Africa. Unfortunately, there is a slow progress in this regard as many of these countries are reluctant to participate in this worthy programme. The infrastructure in most of these countries is not adequate to fully and quickly transport goods and people. The involvement of the private sector in helping IGAD is also limited. Lack of harmonization of policies is another challenge that the IGAD is battling with. Instead of thinking and acting regionally, member states prefer to engage in bilateral agreements with countries of their own. According to the respondents, free movement of people is hampered by a tense relationship among member states. Respondents further said that strict visa regulations and inadequate infrastructure are also discouraging people to move, work and trade. Even though IGAD does not encourage people to people interaction, informal trade along the borders continue to take place. According to the respondents, political will is the key for integration. The lack of political will could be manifested in the overlapping of membership. The region is notorious for subsequent conflicts. Peace in the region could be one of the recipes to bring harmony and stability in the region.

\section{References}

[1] Abdi, I., and Seid, E. (2013). Assessment of economic integration in IGAD. The Horn Economic and Social Policy Institute (HESPI) Policy Papers No. 13/2.

[2] Atin, B., and William, F.S. (2007). On ethnic conflict and the origins of terrorism. Journal of Economic Growth 8: 155-194.

[3] Biswarao, J. (2005).Perspectives on Africa's integration and cooperation: From OAU to AU old Wine in new bottle. Dare Salam: Tanzania Publishing House. 
[4] Dan, K.A. (2010). Study on the comprehensive review of the agreement establishing Intergovernmental Authority on Development (IGAD). Djibouti: Intergovernmental Authority on Development Head Quarter.

[5] Dawit, W.G. (2016). The Wahhabi invasion of Africa. www.zehabesha.com Accessed on 01/07/2016.

[6] Draper, P, Halleson. D, and Alves, P. (2007). SACU, regional integration and the overlap issue in Southern Africa: From Spaghetti to Cannelloni? Johannesburg: The South African Institute of International Affairs.

[7] Economic Commission of Africa (2006). Assessing regional integration in Africa II: Rationalizing regional Economic Communities. Addis Ababa: UNs Economic Commission of Africa.

[8] Estrada, M.A.R. (2009). The global dimension of regional integration model. Available: www.fep.um.edu.my. Accessed on 06/08/2017.

[9] Gerald, W.M. (2012). Examining the political and economic barrier to an IGAD harmonized trade policy. Djibouti: Intergovernmental Authority on Development Head Quarter.

[10] Hettne, B. (2010).Globalisation and the New Regionalism: The second great transformation. New York: St. Martins Publisher.

[11] Haas, E. (1964).The Uniting of Europe: political, social and economic, 1950-1957. Stanford: Stanford University Press.

[12] Institute for security studies (2015). What's next for al-Qaeda in the Horn of Africa? Addis Ababa: ISS monographs.

[13] Kasner,T. (eds) (1983).International regimes. New York: Cornell University Press.

[14] Kidane, M. (2013). The Horn of Africa. UK: Polity Press.

[15] Layne, C. (2006). The unipolar illusion revisited: The coming end of the United States' unipolar moment. International Security, 31(2), 7-41.

[16] Laursen, F. (2008). Theory and practice of regional integration. Jean Monnet/Robert Schuman Paper Series(8)(3). Miami: The Jean Monnet Chair European Union Center of Excellence.

[17] Nomvete, B. (2009). Regional integration in Africa: A path screw with obstacles. The eye on Ethiopia and the Horn of Africa, 17-25. 6 (39).

[18] Peter, W. (2013).Crisis in the Horn of Africa: politics, piracy and the threat of terror. UK: Palgrave MacMillan.

[19] Redie, B. (2013). The Horn of Africa: Intra-state and Inter-state conflicts and security. Sweden: Pluto Press.

[20] Slocum, N., and Langenhov, L.V. (2004). The meaning of regional integration: Introducing positioning theory in regional integration studies. European Integration, 25(3), 227-252.

[21] US Department of State (2009). Human Rights Report: Somalia. http://www.state.gov///dr//rls/hrrpt/2009/af/135976.htm . Accessed on 07/08/2017.

[22] Victoria, D. (2011). Understanding terrorism in the Horn of Africa: American perceptions of Somalia, Kenya and Al Qaeda. (Unpublished)

[23] World Bank (2013). The pirates of Somalia: Ending the threat, rebuilding a nation. Washington: The World Bank.

[24] World Bank (2014). The progress of Africa's regional blocs. Washington: The World Bank. 